\section{Check for updates}

Cite this: Chem. Sci., 2019, 10, 6157

๑ All publication charges for this article have been paid for by the Royal Society of Chemistry

Received 29th January 2019

Accepted 8th May 2019

DOI: $10.1039 / \mathrm{c} 9 \mathrm{sc} 00513 \mathrm{~g}$

rsc.li/chemical-science

\title{
Formation of trigons in a metal-organic framework: The role of metal-organic polyhedron subunits as meta-atoms $\uparrow$
}

\author{
Jiyoung Lee, ${ }^{a}$ Jae Sun Choi, ${ }^{b}$ Nak Cheon Jeong (D) ${ }^{b}$ and Wonyoung Choe (iD) *a
}

Shape control of metal-organic materials on the meso- and macroscale has been an important theme due to emerging properties. Particularly, chemical etching has been useful to create various forms such as core-shells and hollow crystals in metal-organic frameworks. Here we present a unique chemical etching strategy to create trigonal patterned surfaces in metal-organic frameworks. The mechanism suggests that metal-organic polyhedron subunits serve as meta-atoms, playing a crucial role in the formation of trigons on the surface. Such a patterned surface in porous solids can be utilized in metasurface applications in the foreseeable future.

\section{Introduction}

Metal-organic frameworks (MOFs) assembled from metal nodes and organic linkers are highly tunable materials, ${ }^{1-3}$ and now more than 70000 structures are available with several hundred wellestablished topologies. ${ }^{4}$ Precise shape control of MOFs on the meso- and macroscale is becoming a new synthetic challenge because such controlled MOFs open up new opportunities in emerging applications, ${ }^{5-7}$ in addition to conventional ones such as gas storage and catalysis. ${ }^{\mathbf{8} 9}$ Among the several synthetic strategies, such as the templating-assisted method, ${ }^{\mathbf{1 0}, 11}$ defect-engineering method, ${ }^{12}$ perturbation-assisted nanofusion method ${ }^{13,14}$ and polymer coating method, ${ }^{15}$ chemical etching is a simple and straightforward method for synthesizing shape-controlled MOFs, using various etchants such as cyanuric chloride, sodium chloride, hydroquinone, and water. ${ }^{16-19}$ The results of chemical etching are often random shapes, which are evidence of uncontrolled reactions. This clearly indicates the need for a precisely controlled synthetic strategy. A noteworthy example is the work from the Maspoch group, demonstrating unprecedented morphologies of ZIF-8 and ZIF-67 via anisotropic chemical etching. ${ }^{20}$ Kim group synthesized a hierarchical structure having random etching patterns via a size-selective acid etching strategy. ${ }^{21}$ However, shape control still remains a daunting challenge to form regular surface patterns unlike the cases in silicon-based materials..$^{22,23}$

${ }^{a}$ Department of Chemistry, Ulsan National Institute of Science and Technology, Ulsan 44919, Korea.E-mail: choe@unist.ac.kr

${ }^{b}$ Department of Emerging Materials Science, Daegu Gyeongbuk Institute of Science and Technology, Daegu 42988, Korea

$\dagger$ Electronic supplementary information (ESI) available: Details of the materials, instrumentation and synthetic method used. Crystallographic data have been deposited with the Cambridge Crystallographic Data Centre: Deposit number CCDC 1865503 (Zn/Cu-UMOM-10). For ESI and crystallographic data in CIF or other electronic format see DOI: 10.1039/c9sc00513g
While we have studied chemical etching methods to synthesize a MOF built from cuboctahedron metal-organic polyhedra (MOPs), to our surprise, we have found a new strategy to pattern the surface of MOFs with a trigonal shape. The etching strategy is performed by using chemical etching using dimethyl sulfoxide (DMSO) and subsequent transmetalation (Fig. 1). Through this novel synthetic strategy, we successfully obtained MOFs with trigonal surface patterns. Furthermore, these resulting trigons, a well-known phenomenon from atomic to macroscopic levels in carbon-based and boron-nitrogen compounds, ${ }^{\mathbf{2 4 - 2 8}}$ suggest that MOPs serve as meta-atoms.

\section{Results and discussion}

Zn-UMOM-10 (UMOM: UNIST metal-organic material) was selected as a starting material for this study. Zn-UMOM-10 was

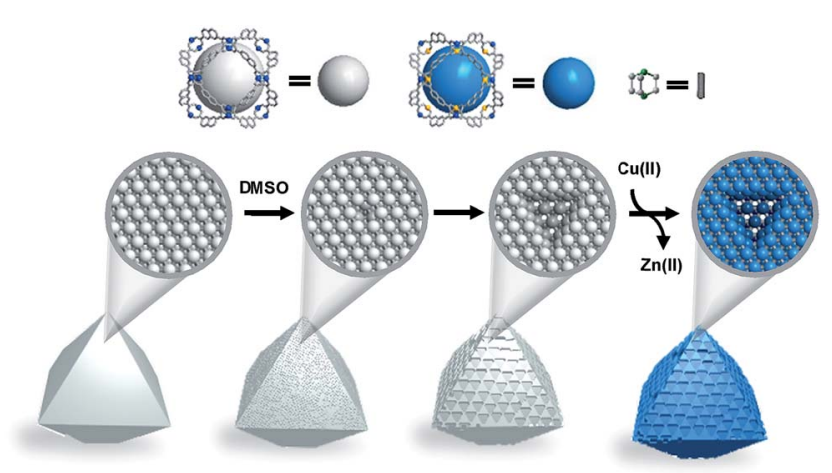

Fig. 1 The schematic illustration of synthesizing $\mathrm{Zn} / \mathrm{Cu}-\mathrm{UMOM}-10$-ce with trigonal patterns on the (111) surface from Zn-UMOM-10. Zn, blue; Cu, yellow; C, grey; O, grey; N, green; all hydrogen atoms and solvent molecules on the paddle-wheel are omitted for clarity. 
obtained by a solvothermal reaction of $\mathrm{Zn}\left(\mathrm{NO}_{3}\right)_{2} \cdot 6 \mathrm{H}_{2} \mathrm{O}, 2$,7naphthalenedicarboxylate (2,7-NDC) and 1,4-diazabicyclo[2.2.2] octane (dabco) in $N, N$-dimethylformamide (DMF) by modifying a previous synthetic method. ${ }^{29}$ A colorless crystal of Zn-UMOM10 was obtained and the X-ray powder diffraction pattern of the as-synthesized Zn-UMOM-10 shows that it has the same structure known as ZND reported by Chun et al. (Fig. S1†). ${ }^{29} \mathrm{Zn}$ UMOM-10 has a ubt topology, composed of a $\mathrm{Zn}_{2}(\mathrm{COO})_{4}$ paddle-wheel as the metal node, and 2,7-NDC and dabco as organic linkers.

Due to the instability of $\mathrm{Zn}$ (II) paddle-wheel MOFs upon axial solvent removal ${ }^{30-33}$ and labile $\mathrm{Zn}-\mathrm{O}$ coordination bonding ${ }^{34}$ we hypothesized that Zn-UMOM-10 could be suitable for the chemical etching reaction. To test such a hypothesis, we synthesized another MOF via a transmetalation reaction with a copper source. When the as-synthesized crystals of Zn-UMOM10 were soaked in $0.1 \mathrm{M} \mathrm{Cu}\left(\mathrm{NO}_{3}\right)_{2}$ solution for 24 hours, blue crystals were collected (Fig. 2a) and their phase purity was confirmed using the X-ray powder diffraction pattern, and subsequently by X-ray single crystal analysis (Fig. 2b, c and Table $\mathbf{S} 1 \dagger$ ). The single crystal structure of this phase confirms that this compound has the same structure as Zn-UMOM-10, except for slight changes in the paddle-wheel node. We find

a
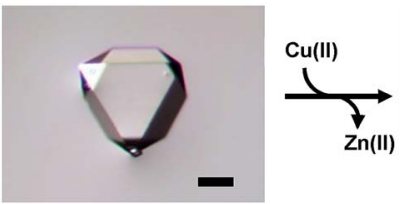

c

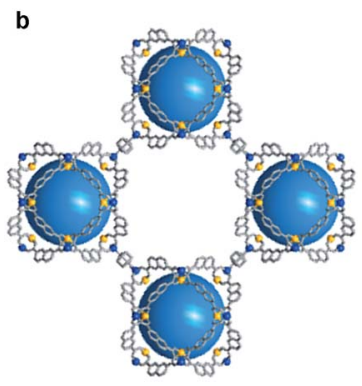

b

d

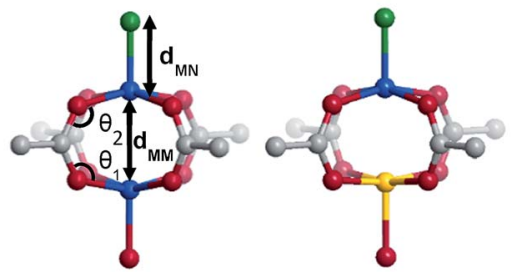

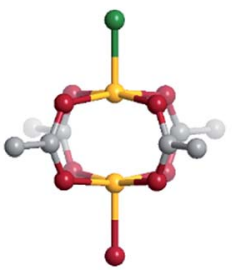

Fig. 2 (a) Optical microscopy images of Zn-UMOM-10 (left) and Zn/ Cu-UMOM-10 (right) after the transmetalation reaction. Scale bar, 100 $\mu \mathrm{m}$. Perspective view of the (b) (100) plane and (c) (111) plane of $\mathrm{Zn} / \mathrm{Cu}$ UMOM-10. Zn, blue; Cu, yellow; C, grey; O, grey; N, grey; all hydrogen atoms and solvent molecules on the paddle-wheel are omitted for clarity. (d) Zn(॥)-Zn(॥) paddle-wheel structures of ZND 27 (left), Zn(॥)$\mathrm{Cu}($ II) paddle-wheel structures of $\mathrm{Zn} / \mathrm{Cu}-U M O M-10$ (middle) and $\mathrm{Cu}($ II)-Cu(॥) paddle-wheel structures of UMOM-2 (ref. 35) (right). Zn, blue; Cu, yellow; C, grey; O, red; N, green. that the two metals coordinated to dabco and solvent are different, resulting in a hetero-bimetallic paddle-wheel system, i.e. $\mathrm{Zn}$ (II) coordinated to dabco and $\mathrm{Cu}(\mathrm{II})$ to solvent molecules. Doonan's group has reported hetero-bimetallic $\mathrm{Pd}(\mathrm{II})-\mathrm{M}$ (II) ( $\mathrm{M}=$ $\mathrm{Cu}, \mathrm{Ni}$, and $\mathrm{Zn}$ ) paddle-wheel systems based on endo-site preferential localization of $\operatorname{Pd}(\mathrm{II})$ because of their square planar geometry. ${ }^{35}$ Maspoch et al. showed the formation of heterobimetallic $\mathrm{Cu}(\mathrm{II})-\mathrm{Zn}$ (II) and $\mathrm{Cu}(\mathrm{II})-\mathrm{Ni}$ (II) paddle-wheel clusters via water-induced single-crystal-to-single-crystal transformation. ${ }^{36}$ We compared the metal-metal distances of the paddle-wheels, $d_{\mathrm{MM}}$, of this and other MOP-based MOFs (Fig. $2 \mathrm{~d}$ and Table S2 $\dagger$ ). Compared to Zn(II)-Zn(II) (2.93 $\AA^{29}$ and Cu(II)$\mathrm{Cu}(\mathrm{II})(2.67 \AA)^{37}$ paddle-wheel distances found in ZND and UMOM-2, respectively, the $d_{\text {MM }}$ found here, $2.74 \AA$, is between these two values. On the other hand, the distance between metal-nitrogen, $d_{\mathrm{MN}}$, is similar to the $d_{\mathrm{MN}}$ found in ZND. In addition, the angle of $\mathrm{C}-\mathrm{O}-\mathrm{Zn}, \theta_{1}\left(128.34^{\circ}\right)$, of this phase is similar to the angle in $\mathrm{ZND}\left(128.08^{\circ}\right)$ and the angle of $\mathrm{C}-\mathrm{O}-\mathrm{Cu}$, $\theta_{2}\left(123.53^{\circ}\right)$, has a similar value to that of UMOM-2 $\left(123.63^{\circ}\right)$. Inductively coupled plasma analysis data show that there is a plateau at about $50 \%$ of the transmetalation reaction even if the reaction time is significantly increased, indicating that the amount of copper and zinc is around 50:50 (Fig. S2 $\dagger$ ). Elemental mapping of a single crystal shows a uniform distribution of $\mathrm{Cu}$ and $\mathrm{Zn}$ (Fig. S3†). Raman spectra also support the hetero-bimetallic paddle-wheel feature. When we exchanged the solvent molecule coordinated to the metal inside the cuboctahedron cage, there is a peak shift only in the $v(\mathrm{Cu}-\mathrm{O})$ region and not in the $v(\mathrm{Zn}-\mathrm{O})$ region (Fig. $\mathrm{S} 4 \dagger)$. We speculated that dabco molecules act as a protective group to hamper metal exchange during the transmetalation reaction. Based on these data, we concluded that this phase is indeed ordered hetero-bimetallic $\mathrm{Zn} / \mathrm{Cu}-\mathrm{UMOM}-10$ with a ubt topology, consisting of facecentered cubic (fcc) packed cuboctahedron cages, assembled from the $\mathrm{ZnCu}(\mathrm{COO})_{4}$ paddle-wheel and 2,7-NDC. Similar formation of bimetallic metal nodes was reported by Sun et al. ${ }^{38}$ They noticed that $\mathrm{Zn}$ (II) coordinated with a dabco molecule was not exchanged to $\mathrm{Cu}$ (II). However, $\mathrm{Zn}$ (II) coordinated to a solvent molecule was exchanged to $\mathrm{Cu}(\mathrm{II}) .{ }^{38} \mathrm{In} \mathrm{Zn} / \mathrm{Cu}-\mathrm{UMOM}-10$, each cuboctahedron cage is surrounded by twelve neighboring identical cages and inter-connected by dabco linkers.

The difference in structural and chemical stability of $\mathrm{Zn}$ UMOM-10 and Zn/Cu-UMOM-10 was tested by their gas sorption analysis and a solubility test in DMSO. To confirm the permanent porosity, $\mathrm{N}_{2}$ sorption isotherms of Zn-UMOM-10 and $\mathrm{Zn} / \mathrm{Cu}$-UMOM-10 were obtained after activation at $30{ }^{\circ} \mathrm{C}$ for $6 \mathrm{~h}$. After activation, the color of Zn-UMOM-10 changed from colorless to yellow, indicating the structural decomposition. ${ }^{35}$ Also, we failed to obtain the $\mathrm{N}_{2}$ sorption isotherm even after several attempts. Unlike Zn-UMOM-10, the permanent porosity of $\mathrm{Zn} / \mathrm{Cu}-\mathrm{UMOM}-10$ was confirmed by their $\mathrm{N}_{2}$ sorption isotherm and BET surface area of $3270 \mathrm{~m}^{2} \mathrm{~g}^{-1}$, similar to the calculated surface area of $3570 \mathrm{~m}^{2} \mathrm{~g}^{-1}$ by using the Zeo++ program $^{39,40}$ with a $1.8 \AA$ probe radius which is the same as the $\mathrm{N}_{2}$ radius (Fig. 3a). When we soaked single crystals of $\mathrm{Zn}$ UMOM-10 and Zn/Cu-UMOM-10 in DMSO, the crystal of ZnUMOM-10 dissolved within a few hours, but there was no 
a

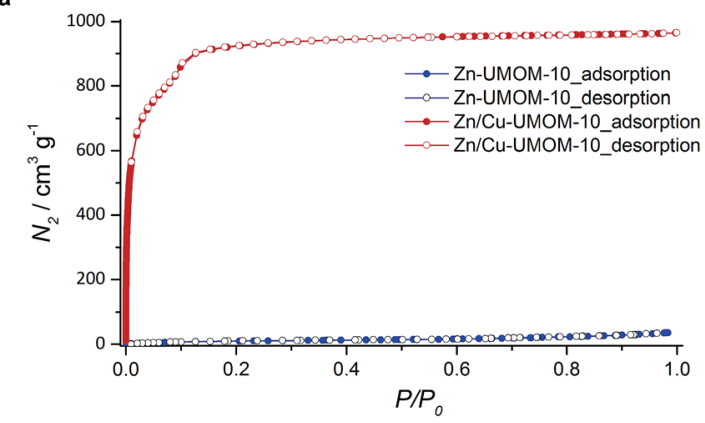

b

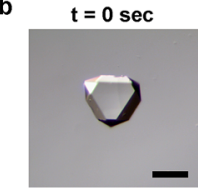

c
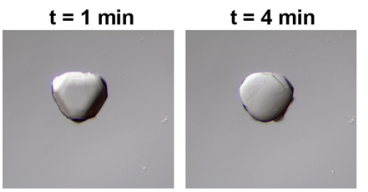

$\mathbf{t}=\mathbf{1}$ day
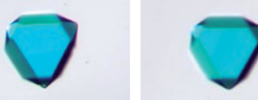

$\mathbf{t}=\mathbf{3}$ days

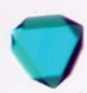

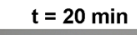

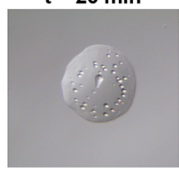

$t=7$ days

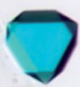

Fig. 3 (a) The $\mathrm{N}_{2}$ sorption isotherm of $\mathrm{Zn}-\mathrm{UMOM}-10$ and $\mathrm{Zn} / \mathrm{Cu}-$ UMOM-10 at $77 \mathrm{~K}$ after activating at $30^{\circ} \mathrm{C}$ for $6 \mathrm{~h}$. Time-lapse images: a single crystal of (b) Zn-UMOM-10 and (c) Zn/Cu-UMOM-10 in DMSO. Scale bar, $100 \mu \mathrm{m}$.

change in the crystals of $\mathrm{Zn} / \mathrm{Cu}-\mathrm{UMOM}-10$ (Fig. 3b). Indeed, the $\mathrm{X}$-ray powder diffraction patterns show that the crystallinity was well-maintained when we soaked $\mathrm{Zn/Cu}$-UMOM-10 in DMSO for 7 days (Fig. S5†). We speculate that these stability differences between $\mathrm{Zn}-\mathrm{UMOM}-10$ and $\mathrm{Zn} / \mathrm{Cu}-\mathrm{UMOM}-10$ represent different binding energies of $\mathrm{Zn}$-dabco in $\mathrm{Zn}$ (II) paddle-wheel and $\mathrm{Zn}$ (II)$\mathrm{Cu}(\mathrm{II})$ hetero-bimetallic paddle-wheel cases similar to the binding energy difference between $\mathrm{CO}_{2}$ and metal centers in each case. ${ }^{\mathbf{4 1}} \mathrm{A}$ plausible mechanism for the dissolution of $\mathrm{Zn}$ UMOM-10 is the following (Fig. 4). A dabco molecule coordinated to the $\mathrm{Zn}$ (II) paddle-wheel is replaced by a DMSO molecule because the distance between two paddle-wheels is too short for two DMSO molecules to coordinate. Such an event will create different paddle-wheel metal centers; one is an axial coordination site occupied with a DMSO molecule, and the other is unoccupied. After replacement, structural deformation occurs due to the changes of the coordination number of $\mathrm{Zn}^{2+}$ in the unoccupied axial site. The structural instability of the $\mathrm{Zn}$ (II) paddle-wheel in the absence of the axial solvent has been wellestablished by several previous studies. ${ }^{30-32}$

Based on such different stabilities, Zn/Cu-UMOM-10-ce (ce stands for chemical etching) was obtained after an etching reaction with dilute DMSO, followed by a transmetalation reaction of $\mathrm{Cu}(\mathrm{II})$. When we used pure DMSO during the etching reaction of $\mathrm{Zn}-\mathrm{UMOM}-10$, the reaction was too fast as we demonstrated. Therefore, dilute DMSO in DMF is used as an etchant instead of pure DMSO to slow down the etching reaction. Optical microscopy images show that there is no morphology change after reactions (Fig. 5a-c). Their crystallinity was maintained after $24 \mathrm{~h}$ of etching and transmetalation reactions, as shown in X-ray powder diffraction analysis

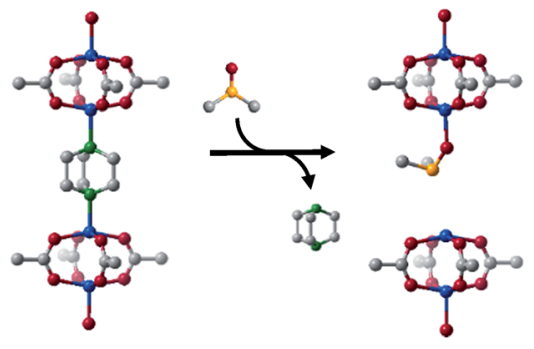

b
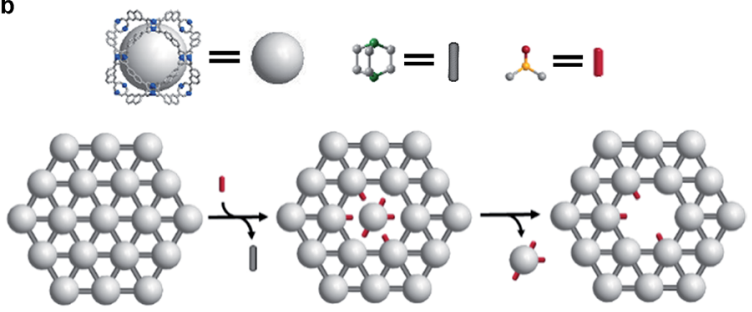

Fig. 4 A proposed trigon formation in the presence of DMSO. (a) A part of the structure of $\mathrm{Zn}-\mathrm{UMOM}-10$ after the replacement reaction with DMSO. Zn, blue; C, grey; O, red; N, green; S, orange; all hydrogen atoms are omitted for clarity. (b) The schematic illustration of the (111) plane of $\mathrm{Zn-UMOM-10}$ during the replacement reaction.
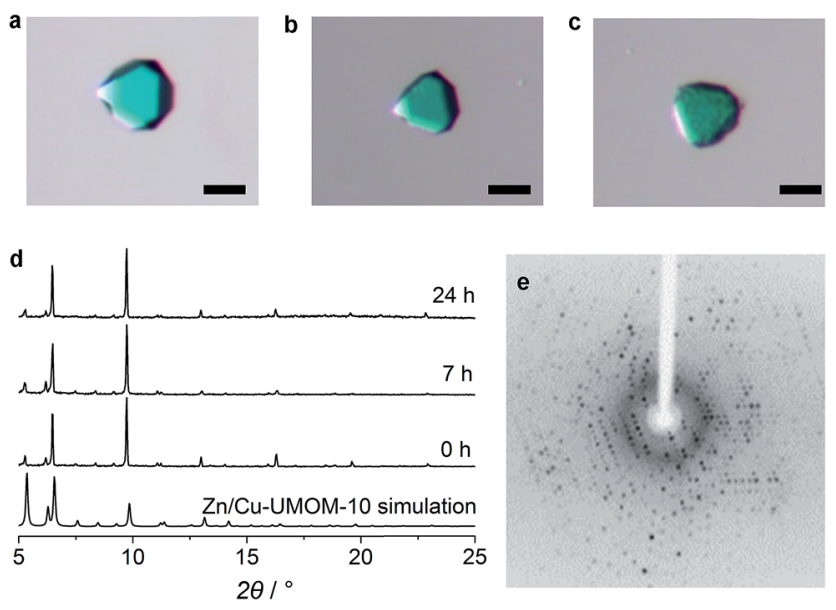

Fig. 5 Optical microscopy images of (a) Zn/Cu-UMOM-10, (b) Zn/CuUMOM-10-ce with an etching time of $7 \mathrm{~h}$, and (c) Zn/Cu-UMOM-10ce with an etching time of $24 \mathrm{~h}$. Scale bar, $50 \mu \mathrm{m}$. (d) Powder X-ray diffraction patterns of Zn/Cu-UMOM-10 and Zn/Cu-UMOM-10-ce with an etching time of $7 \mathrm{~h}$ and $24 \mathrm{~h}$. (e) Single crystal $\mathrm{X}$-ray diffraction patterns of $\mathrm{Zn} / \mathrm{Cu}-\mathrm{UMOM}-10$-ce after $48 \mathrm{~h}$ etching reaction, followed by the transmetalation reaction of $\mathrm{Cu}(॥)$.

(Fig. 5d). Surprisingly, their single crystallinity was maintained after $48 \mathrm{~h}$ of etching reaction as shown in Fig. 5e. Scanning electron microscopy (SEM) images reveal a peculiar pattern in the surface of $\mathrm{Zn} / \mathrm{Cu}-\mathrm{UMOM}-10$-ce. Micro-sized trigonal patterns can be seen on the surface of crystals (Fig. 6a-d). After $7 \mathrm{~h}$ of etching reaction, a few micro-sized trigonal patterns appeared on the surface of the (111)-type face. Interestingly, when we increased the etching reaction time, the trigons aggregated, and the surface became rougher (Fig. S6†). The formation of these trigonal patterns can be rationalized by 

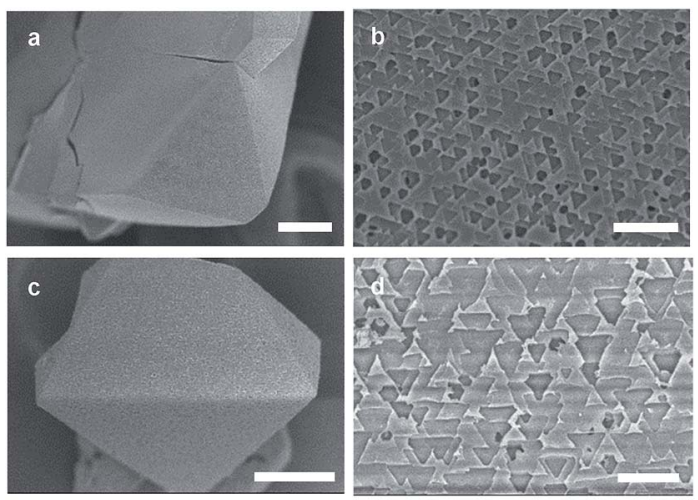

e
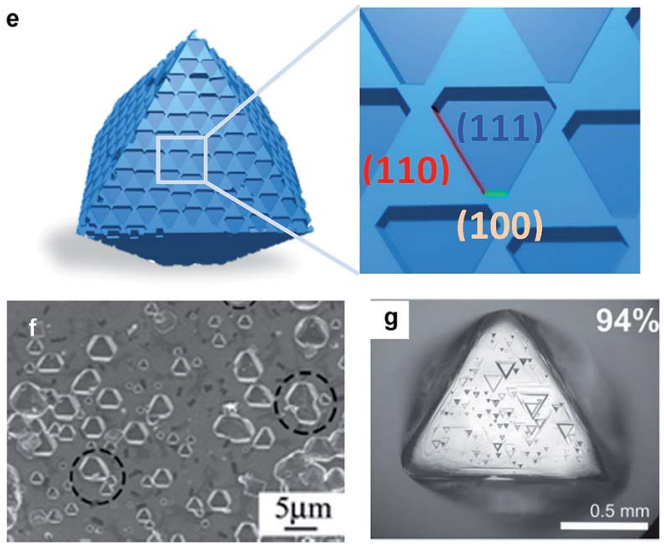

Fig. 6 SEM images of $\mathrm{Zn} / \mathrm{Cu}-\mathrm{UMOM}-10$-ce with an etching time of (a and b) $7 \mathrm{~h}$ and (c and d) $24 \mathrm{~h}$. Scale bar (a and c) $50 \mu \mathrm{m}$, (b and d) $10 \mu \mathrm{m}$. (e) Illustration of the crystal morphology of Zn/Cu-UMOM-10-ce. Crystallographic planes of (111), (110) and (100) are represented in blue, red and green, respectively. Photographs of etching patterns on a (111) face of (f) silicon wafer. ${ }^{23}$ Copyright 2009 Rights Managed by the Royal Society of Chemistry. (g) A single crystal of diamond. ${ }^{25}$ Copyright 2007 Rights Managed by the Mineralogical Society of America.

anisotropic etching, caused by different etching rates in the [111], [110], and [100] directions (Fig. 6e). These horizontal etching phenomena represent that there is a preferential etching reaction along the [110] and [100] directions compared to the etching reaction along the [111] direction. Because of the different numbers of exposed dabco per unit area of each plane, (111) $:(100):(110)=3 \sqrt{ } 3: 2: 2$, there are different etching rates in each plane. In other words, the etching reaction takes place quickly in the plane having a small number of dabco molecules. Such a phenomenon is quite similar to anisotropic etching on the (111) surface of silicon which shows that the etching rate is different depending on the number of dangling bonds in each plane. ${ }^{42}$ Furthermore, focused ion beam images show that these patterns exist only on the surface of crystals (Fig. S7 $\dagger$ ). Such a phenomenon is quite similar to the etching patterns in a platinum electrode which is composed of fcc packed platinum atoms (Fig. S8†). ${ }^{43}$ The triangular etched pits were formed when cathodic corrosion occurred on the (111)type surface. A diamond and silicon also have similar trigonal patterns on their (111) face after thermal/chemical etching (Fig. $6 \mathrm{f}$ and $\mathrm{g}$ ). ${ }^{23-27}$ Based on structural similarity between $\mathrm{Zn} /$ $\mathrm{Cu}-\mathrm{UMOM}-10-\mathrm{ce}$ and these known examples, we speculate that cuboctahedron MOP cages in Zn-UMOM-10 are acting as 'meta-atoms' such as platinum and carbon atoms in fcc Pt and diamond structures, respectively, during the etching reaction.

The permanent porosity and the micro/mesoporosity of $\mathrm{Zn} /$ $\mathrm{Cu}-\mathrm{UMOM}-10$-ce are confirmed by their $\mathrm{N}_{2}$ sorption isotherm at $77 \mathrm{~K}$. The $\mathrm{Zn} / \mathrm{Cu}-\mathrm{UMOM}-10$-ce has a BET surface area of 3310 $\mathrm{m}^{2} \mathrm{~g}^{-1}$ and there is no difference compared to that of $\mathrm{Zn} / \mathrm{Cu}$ UMOM-10 (Fig. S9a $\dagger$ ). We confirmed that there are three different micropores of $\mathrm{Zn} / \mathrm{Cu}-\mathrm{UMOM}-10-c e$, which were analyzed using a DFT model. These three different pores at 1.88, 2.17 and $2.30 \mathrm{~nm}$ are well-matched with the micropores of $\mathrm{Zn} /$ Cu-UMOM-10 except for a slightly reduced pore volume (Fig.$\mathrm{S} 9 \mathrm{~b} \dagger$ ). Interestingly, there is an increase in $\mathrm{N}_{2}$ uptake amount at high pressure due to the slight increase of mesoporous features of $\mathrm{Zn} / \mathrm{Cu}$-UMOM-10-ce on the surface of crystals during the etching reaction unlike the result for $\mathrm{Zn} / \mathrm{Cu}$-UMOM-10. After etching, macroporous features of $\mathrm{Zn} / \mathrm{Cu}$-UMOM-10-ce were observed. Pore size distribution data in the macropore range (50-5000 $\mathrm{nm}$ ) obtained by mercury porosimetry show the macroporosity of Zn/Cu-UMOM-10-ce (Fig. S10b $\dagger$ ) unlike for Zn/ Cu-UMOM-10.

\section{Conclusions}

In summary, we demonstrated a new etching strategy to create a patterned MOF. The trigonal patterned MOF (Zn/Cu-UMOM10-ce) was synthesized as the first example via chemical etching, followed by a transmetalation reaction. The formation of trigonal patterns on the (111)-type surface of $\mathrm{Zn} / \mathrm{Cu}-\mathrm{UMOM}$ 10-ce is similar to the well-known phenomenon in fcc Pt and diamond/silicon structures having a diamond atomic structure. Based on the structural similarity found in those materials, we suggest a plausible mechanism for the etching reaction, suggesting that cuboctahedron MOP cages act as sacrificial metaatoms, just like Pt atoms. Furthermore, we demonstrated that the origin of the macroporous feature of $\mathrm{Zn} / \mathrm{Cu}-\mathrm{UMOM}-10$-ce comes from these etching patterns. We expect that this novel chemical etching strategy, together with the concept, could be utilized as a significant tool for modifying the surface properties of materials (e.g. controlling hydrophobicity and surface functionalization via area selective atomic layer deposition), ${ }^{\mathbf{4 4 5}}$ and further fabricating a meta-surface with a periodic or quasiperiodic two-dimensional planar arrangement of metaatoms. ${ }^{46-49}$ A good example is the plasmonic meta-surface having a triangle hole-array of the metal nanostructure which produces countercircularly polarized second-harmonic generation beams although the material itself is achiral. ${ }^{49}$

\section{Conflicts of interest}

There are no conflicts to declare.

\section{Acknowledgements}

This work was supported by the National Research Foundation of Korea (NRF-2016R1A5A1009405, NRF-2015R1D1A1A0206173 8 and NRF-2014K1A3A1A09063072). The authors acknowledge 
Pohang Accelerator Laboratory (PAL) for 2D beamline use (20171st-2D-032) and would like to thank Professor Hyun Sung Kim at Pukyong National University for the macropore measurement.

\section{Notes and references}

1 H. Furukawa, K. E. Cordova, M. O'Keeffe and O. M. Yaghi, Science, 2013, 341, 123044.

2 W. Lu, Z. Wei, Z.-Y. Gu, T.-F. Liu, J. Park, J. Park, J. Tian, M. Zhang, Q. Zhang, T. Gentle III, M. Bosch and H.-C. Zhou, Chem. Soc. Rev., 2014, 43, 5561-5593.

3 H.-C. Zhou, J. R. Long and O. M. Yaghi, Chem. Rev., 2012, 112, 673-674.

4 P. Z. Moghadam, A. Li, S. B. Wiggin, A. Tao, A. G. P. Maloney, P. A. Wood, S. C. Ward and D. Fairen-Jimenez, Chem. Mater., 2017, 29, 2618-2625.

5 L.-G. Qiu, T. Xu, Z.-Q. Li, W. Wang, Y. Wu, X. Jiang, X.-Y. Tian and L.-D. Zhang, Angew. Chem., Int. Ed., 2008, 47, 9487-9491.

6 Y. Yue, P. F. Fulvio and S. Dai, Acc. Chem. Res., 2015, 48, 3044-3052.

7 Z. Fang, B. Bueken, D. E. De Vos and R. A. Fischer, Angew. Chem., Int. Ed., 2015, 54, 7234-7254.

8 C. Perego and R. Millini, Chem. Soc. Rev., 2013, 42, 39563976.

9 M. E. Davis, Nature, 2002, 417, 813.

10 H. Huang, J.-R. Li, K. Wang, T. Han, M. Tong, L. Li, Y. Xie, Q. Yang, D. Liu and C. Zhong, Nat. Commun., 2015, 6, 8847.

11 W. Zhang, Y. Liu, G. Lu, Y. Wang, S. Li, C. Cui, J. Wu, Z. Xu, D. Tian, W. Huang, J. S. DuCheneu, W. D. Wei, H. Chen, Y. Yang and F. Huo, Adv. Mater., 2015, 27, 2923-2929.

12 K. M. Choi, H. J. Jeon, J. K. Kang and O. M. Yaghi, J. Am. Chem. Soc., 2011, 133, 11920-11923.

13 Y. Yue, Z.-A. Qiao, P. F. Fulvio, A. J. Binder, C. Tian, J. Chen, K. M. Nelson, X. Zhu and S. Dai, J. Am. Chem. Soc., 2013, 135, 9572-9575.

14 Y. Yue, A. J. Binder, R. Song, Y. Cui, J. Chen, D. K. Hensley and S. Dai, Dalton Trans., 2014, 43, 17893-17898.

15 J. Yi, H. Li, L. Jiang, K. Zhang and D. Chen, Chem. Commun., 2015, 51, 10162-10165.

16 Y. Yoo and H.-K. Jeong, Chem. Eng. J., 2012, 181, 740-745.

17 G. Wang, Z. Xu, Z. Chen, W. Niu, Y. Zhou, J. Guo and L. Tan, Chem. Commun., 2013, 49, 6641-6643.

18 A. Ahmed, N. Hodgson, M. Barrow, R. Clowes, C. M. Robertson, A. Steiner, P. McKeown, D. Bradshaw, P. Myers and H. Zhang, J. Mater. Chem. A, 2014, 2, 90859090.

19 Y. Kim, T. Yang, G. Yun, M. B. Ghasemian, J. Koo, E. Lee, S. J. Cho and K. Kim, Angew. Chem., Int. Ed., 2015, 54, 13273-13278.

20 C. Avci, J. Ariñez-Soriano, A. Carné-Sánchez, V. Guillerm, C. Carbonell, I. Imaz and D. Maspoch, Angew. Chem., Int. Ed., 2015, 54, 14417-14421.

21 J. Koo, I.-C. Hwang, X. Yu, S. Saha, Y. Kim and K. Kim, Chem. Sci., 2017, 8, 6799-6803.

22 Z. Huang, N. Geyer, P. Werner, J. de Boor and U. Gösele, Adv. Mater., 2011, 23, 285-308.
23 H. Wang, G. Li, L. Jia, L. Li and G. Wang, Chem. Commun., 2009, 3786-3788.

24 J. F. H. Custers and H. R. Simpson, Nature, 1954, 173, 738.

25 Y. Fedortchouk, D. Canil and E. Semenets, Am. Mineral., 2007, 92, 1200-1212.

26 A. R. Patel and S. M. Patel, J. Phys. D: Appl. Phys., 1968, 1, 1445.

27 A. R. Patel, Physica, 1962, 28, 44-51.

28 G. H. Ryu, H. J. Park, J. Ryou, J. Park, J. Lee, G. Kim, H. S. Shin, C. W. Bielawski, R. S. Ruoff, S. Hong and Z. Lee, Nanoscale, 2015, 7, 10600-10605.

29 H. Chun, H. Jung and J. Seo, Inorg. Chem., 2009, 48, 20432047.

30 M. K. Bhunia, J. T. Hughes, J. C. Fettinger and A. Navrotsky, Langmuir, 2013, 29, 8140-8145.

31 S. Bureekaew, S. Amirjalayer and R. Schmid, J. Mater. Chem., 2012, 22, 10249-10254.

32 J. I. Feldblyum, M. Liu, D. W. Gidley and A. J. Matzger, J. Am. Chem. Soc., 2011, 133, 18257-18263.

33 X. Song, T. K. Kim, H. Kim, D. Kim, S. Jeong, H. R. Moon and M. S. Lah, Chem. Mater., 2012, 24, 3065-3073.

34 Z. Wei, W. Lu, H.-L. Jiang and H.-C. Zhou, Inorg. Chem., 2013, 52, 1164-1166.

35 J. M. Teo, C. J. Coghlan, J. D. Evans, E. Tsivion, M. HeadGordon, C. J. Sumby and C. J. Doonan, Chem. Commun., 2016, 52, 276-279.

36 J. Albalad, J. Arinez-Soriano, J. Vidal-Gancedo, V. Lloveras, J. Juanhuix, I. Imaz, N. Aliaga-Alcalde and D. Maspoch, Chem. Commun., 2016, 52, 13397-13400.

37 J. Lee, J. H. Kwak and W. Choe, Nat. Commun., 2017, 8, 14070.

38 P.-P. Cui, X.-D. Zhang, P. Wang, Y. Zhao, M. Azam, S. I. AlResayes and W.-Y. Sun, Inorg. Chem., 2017, 56, 14157-14163.

39 T. F. Willems, C. H. Rycroft, M. Kazi, J. C. Meza and M. Haranczyk, Microporous Mesoporous Mater., 2012, 149, 134-141.

40 R. L. Martin, B. Smit and M. Haranczyk, J. Chem. Inf. Model., 2012, 52, 308-318.

41 Z. Ruyi, L. Pei-Zhou, Z. Yong-Fei, L. Jia, Z. Ruo, D. Hui, L. Zhong, W. Jin-Gui, Z. Ruqiang and Z. Yanli, Small, 2016, 12, 2334-2343.

42 H. Seidel, L. Csepregi, A. Heuberger and H. Baumgärtel, J. Electrochem. Soc., 1990, 137, 3612-3626.

43 T. J. P. Hersbach, A. I. Yanson and M. T. M. Koper, Nat. Commun., 2016, 7, 12653.

44 L. Lu, X.-Y. Li, X.-Q. Liu, Z.-M. Wanga and L.-B. Sun, J. Mater. Chem. A, 2015, 3, 6998-7005.

45 X.-Y. Xie, X.-Y. Qian, S.-C. Qi, J.-K. Wu, X.-Q. Liu and L.-B. Sun, ACS Sustainable Chem. Eng., 2018, 6, 13217-13225.

46 A. V. Kildishev, A. Boltasseva and V. M. Shalaev, Science, 2013, 339, 1232009.

47 C. M. Soukoulis and M. Wegener, Nat. Photonics, 2011, 5, 523.

48 G. Li, S. Zhang and T. Zentgraf, Nat. Rev. Mater., 2017, 2, 17010.

49 K. Konishi, T. Higuchi, J. Li, J. Larsson, S. Ishii and M. Kuwata-Gonokami, Phys. Rev. Lett., 2014, 112, 135502. 